tha test flies had mated. The mated status of a male should be detectable with better than 90 per cent accuracy up to a week after mating. I am still investigating the apparent decline in accuracy of the test for longer times after mating.

The anatomy of the male terminalia in $L$. cuprina closely resembles that of $I$. sericata, and the test is likcly to have cqual validity in that insect. Phormia terrae novae, Calliphora vicina and $C$. vomitoria all have lateral penis ducts, and in fresh specimens of the last species $I$ have observed male accessory gland secretion in the lateral penis ducts. It may well be that other more advanced flies, in addition to the calliphorines, will be found to have similar structures.

I thank Dr C. T. Lewis for his advice and encouragement. The work was supported by a grant from the Agricultural Research Council.

Impcrial College Field Station,

JoH: POLLOCK

Ascot, Berkshire.

Reccived June 9, 1969.

${ }^{1}$ MacLeod, J., and Donnelly, J., Entomologia Exp. Appl., 4, 101 (1961).

\section{Molecular Structure of Herbicides and their Sorption by Soils}

PARTition between soil and water of organic compounds that do not ionize in the $p \mathrm{H}$ range $4-8$ is closely correlated with the soil's content of organic matter. Lambert ${ }^{1}$ and Furmidge and Osgerby ${ }^{2}$ have expressed sorption in terms of partition coefficients between soil organic matter and water, neglecting mineral constituents. Some investigators have also reported inverse correlations between water solubility and sorption on soil whereas others have found no relationship ${ }^{2,3}$. Little is known about the mechanisms of sorption on soil, but apparently only a small fraction of the surface is responsible for the sorption of certain herbicides ${ }^{3}$. I have attempted to learn more about sorption mechanisms by studying how changes in the chemical structure of related compounds affect sorption.

Sorption isotherms were determined by a wet slurry technique, for twenty-two substituted phenylureas and a homologous series of alkyl-N-phenyl carbamates on four neutral Rothamsted soils containing from 1 to 4 per cent organic matter. The partition coefficient, $K$, was deter-

Table 1. PARTITION COEFFICIENTS OF SUBSTIRUTED PHENYLUREAS

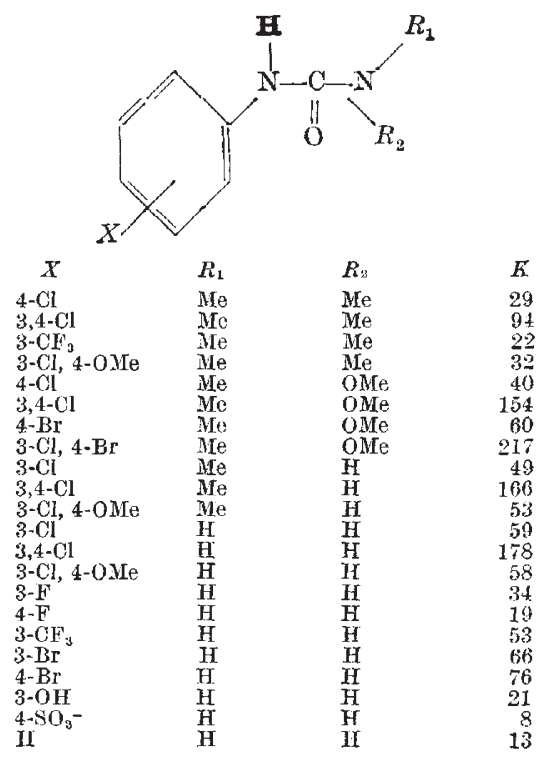

Table 2. PARTITIOA COEFFICIENTS OF ALKYL-N-PHENYLCARBAMATES

$\begin{array}{lr}\quad R & \boldsymbol{K} \\ \text { Methyl } & 31 \\ \text { Ethyl } & 38 \\ \text { Propyl } & 66 \\ \text { Iso-propyl } & 51 \\ \text { Butyl } & 104 \\ \text { Pentyl } & 236\end{array}$

mined from the linear relationship $x=K c$, where $x$ is compound sorbed per unit weight of organic matter in the soil and $c$ is the equilibrium concentration. For each compound, $K$ was approximately constant for the four soils and mean values were used.

The substituted phenylureas (Table 1) gave a linear relationship between $\log K$ and $\sigma$, the Hammett constant* for meta and para substituents in the phenyl ring, and $70 \cdot 5$ per cent of the variation in $\log K$ was accounted for by $\sigma$. A significant improvement $(75 \cdot 5$ por cent of variation) was abtained using a combination of $\sigma$ and the Taft constants ${ }^{4}$ for substituents on the side-chain nitrogen. Of the alternative relationships examined based on free energy contributions of substituent groups, none was better than $\sigma$. Hansch's $\pi$ constant $^{5}$, derived from partition between 1 -octanol and water, accounted for 50.1 per cent of the variation. Parachor $(7.5$ per cent of variation), used by Lambert ${ }^{1}$ as a measure of the energy required for a molecule to stay in solution, and parachor $-45 \mathrm{~N}$ (24.6 per cent of variation), where $N$ is the number of possible hydrogen bonding sites in the molecule', were poor predictors of sorption. Water solubility of the phenylureas used was not a factor in determining their sorption.

In contrast to the results with the substituted phenyl. ureas, those (Table 2) with alkyl-N-phonylcarbamates show a much better linear relationship between $\log K$ and $\pi$. Each additional methylene group increases parachor, so that the linear relationship between $\log K$ and parachor found by Lambert ${ }^{1}$ for 2,6-dinitro-4alkylsulphonyl-NN-dialkylanilines is also observed. A plot of $\log K$ against $\pi$ of Lambert's results is, however, also linear with a slope similar to that given by the phenylcarbamates. Each additional methylene group decreases water solubility so that an inverse relationship with water solubility would also be expected for these compounds.

For the phenylureas without long alkyl side-chains. ring de-activation by substituents in the ring, or by replacement of a methyl group on the side-chain nitrogen by hydrogen or methoxyl, seems the factor controlling sorption, possibly through charge-transfer bonding to activated sites on organic matter. Similar bonding by activated rings to de-activated sites on organic matter could occur. The Hammett and Taft constants are a measure of the de-activating effect of the substituents. The electron distribution in the ring is about the same in the various alkyl- $\mathrm{N}$-phenylcarbamates and changes in. sorption are caused by increasing lipophilicity with incrcasing length of the alkyl chain. Their sorption is probably an accumulation at hydrophobic sitos at the organic matter/water interface in a way similar to surface. active agents. $\pi$ is a measure of lipophilicity or hydrophilic-hydrophobic balance ${ }^{7}$ and seems to express these properties better than parachor or water-solubility.

The sorption behaviour of any group of non-ionie organic compounds in soils can probably best be accounted for on the basis of their Hammett, Taft and $\pi$ constants.

Rothamsted Experimental Station,

G. G. Brigas

Harpenden, Hertfordshire.

Received July 21, 1969.

${ }^{1}$ Lambert, S. M., J. Agric. Food Chem., 15, 572 (1967),

2 Furmidge, C. G. L, and Osgerby, J. M., J. Sci. Food Agric.,18, 269 (1967).

${ }^{3}$ Hance, R. J., Weed Res., 5, 98 (1965).

- Barlin, G. B., and Perrin, D. D., Quart. Rev. Chem. Soc., 20, 75 (1966).

${ }_{5}^{5}$ Fujita, 'T., Iwasa, J., and Hansch, C., J. Amer. Chem. Soc., 86, 5175 (1964).

${ }^{6}$ Hance, R. J., J. Agric. Food Chem., 17, 66t (1969).

' Hance, R. J., Nature, 214, 630 (1967). 